The authors highlight a rare type of parotid gland tumour, presenting past and contemporary treatment options for this entity, and underscore the necessity of therapy individualization in every single case. Acinic cell carcinoma (ACC) is a rare salivary gland tumour accounting for 6 to $15 \%$ of all malignant neoplasms of the parotid gland. Although ACC belongs to low-grade malignant tumours, there can be seen ones with aggressive behaviour, rapid progression and a tendency to metastasize. We present a case of a locally advanced ACC without clinically detectable metastases. Diagnostic imaging (MRI and USG) and a surgical biopsy were performed to establish the diagnosis and assess the extent of this huge tumour. The patient was qualified for surgery (total parotidectomy with MRND III). The postoperative period was complicated by partial necrosis of the skin flap used to close the pre-auricular area defect. There was no postoperative radiotherapy because of the lack of nodal involvement and the prolonged wound healing. After 24 months of postoperative follow-up there is no evidence of recurrence of the tumour.

Key words: acinic cell carcinoma, total parotidectomy, treatment individualisation.

\section{Acinic cell carcinoma of the parotid gland. Case report}

\author{
Jarosław Dąbrowski, Tomasz Piętka, Jan Przybysz, Grzegorz Krzymański
}

Department of Maxillofacial Surgery, Military Institute of Medicine, Warsaw

\section{Introduction}

Acinic cell carcinoma (ACC) is one of the rarely occurring malignant salivary gland tumours. Despite it being known from the beginning of the $20^{\text {th }}$ century (Nasse 1892), Foote and Frazell (1953) were the first to take into consideration the potentially malignant behaviour of ACC [1]. The tumour affects mostly the parotid glands and comprises $6-15 \%$ of all salivary gland malignancies [2]. Acinic cell carcinoma is the fourth most common malignant parotid gland tumour after mucoepidermoid carcinoma (MEC), adenoid cystic carcinoma (AdCC) and carcinoma ex pleomorphic adenoma. Acinic cell carcinoma occurs in the parotid gland more often than primary planoepithelial carcinoma. Besides the parotid gland the tumour can be seen in the submandibular gland, lacrimal glands and minor salivary glands of the oral cavity, throat and larynx [3]. In comparison to other salivary gland malignancies (adenoid cystic carcinoma or salivary duct carcinoma) ACC malignancy is quite low. This is reflected in the high level of 10 -year survival rates (70\%).

The tumour is seen predominantly among white people, mainly between the $5^{\text {th }}$ and $6^{\text {th }}$ decade of life. Males suffer twice as often as females. Acinic cell carcinoma is the third most common bilateral salivary gland tumour after Warthin tumour and pleomorphic adenoma (3\% of cases) [3].

Typical acinic cell carcinoma appears as a solitary, soft, slowly-growing, painless, encapsulated mass that gradually enlarges (usually over a period of several years) the affected gland. This can result in facial asymmetry. In the literature there are a few descriptions of approximately 40 years of ACC progression leading to a huge tumour [4]. Pain is not a typical sign of ACC and can be an effect of an intra-tumoural haemorrhage [5]. Evidence of facial nerve involvement with paresis or paralysis (present in 3-7.5\% of cases) seems to be an ominous sign. Tumour diameter greater than $3 \mathrm{~cm}$ and adjacent tissue invasion are found to be other unfavourable prognostic factors $[3,5]$. Sometimes ACC coexists with pituitary adenoma or releases ACTH, leading to Cushing syndrome $[6,7]$.

Ultrasonography, magnetic resonance imaging (MRI) or computed tomography $(\mathrm{CT})$ imaging findings are usually similar to those seen in benign parotid gland neoplasms [8]. The diagnosis is established on the basis of tumour biopsy, predominantly fine needle one. Ultrasonography, CT, and MRI enable meticulous evaluation of tumour size and involvement of adjacent anatomical structures and are helpful in the preoperative planning of the surgical procedure.

Macroscopically, ACC is a solid, homogeneous, yellow-grey mass on the diameter. There is a lack of heterogeneous myxoid areas typical for pleomorphic adenoma. Microscopically, ACC is defined as a malignant epithelial neoplasm in which at least some cells demonstrate differentiation towards acinar cells. Ultrastructural studies, however, have demonstrated that the tumour is not absolutely homogeneous. There can be found cell lines that resemble ductal cells and myoepithelial cells [3, 9, 10]. In accordance with the facts mentioned above, 4 principle histopathological variants are distinguished:

- solid,

- microcystic,

- papillary-cystic,

- follicular. 
Batsakis, from the microscopic point of view, divides acinic cell carcinomas into 2 groups: low-grade and highgrade tumours. Features that distinguish these 2 groups are: blood vessel involvement, finger-like invasion of adjacent tissues and the presence of some particular histological subtypes (solid tumours) [11]. This simple classification seems to have some limited prognostic value and it is often used in clinical practice. Other bad prognostic factors are extracapsular spread, facial nerve paralysis and the presence of regional lymph node metastases.

Because ACC is a rare salivary gland tumour there are only a few publications in the literature presenting large uniform series of patients suffering from this disease [5, 11]. This situation makes it difficult to create an algorithm of ACC treatment. In the mid $20^{\text {th }}$ century ACCs, also called acino-lobular tumours at that time, were treated by simple enucleation. Repeated notifications about recurrences led to the application of more radical procedures [1]. Total parotidectomy with neck dissection for regional lymph node removal was the treatment of choice in the 1960s. Its supporters were convinced about aggressive behaviour of the tumour in spite of the lack of clinical observations confirming this speculation [12]. On the other hand, Goodwin considered tumour removal within the limits of unaffected tissues to be the most appropriate way of treatment. A similar opinion is held by Kim and Mathog. They recommend a superficial parotidectomy for tumours of the superficial lobe of the parotid gland and a total parotidectomy with facial nerve sparing for neoplasms located in the deep lobe of the parotid gland [13]. Facial nerve involvement and coexisting malignant salivary gland tumour are indications for radical total parotidectomy.

Acinic cell carcinoma rarely metastasizes to regional lymph nodes (about 10\% of cases). This is why the elective neck dissection is usually not advocated [14]. The presence of clinically conspicuous lymph nodes is an indication for selective neck dissection. According to intraoperative histopathological examination the procedure may need to

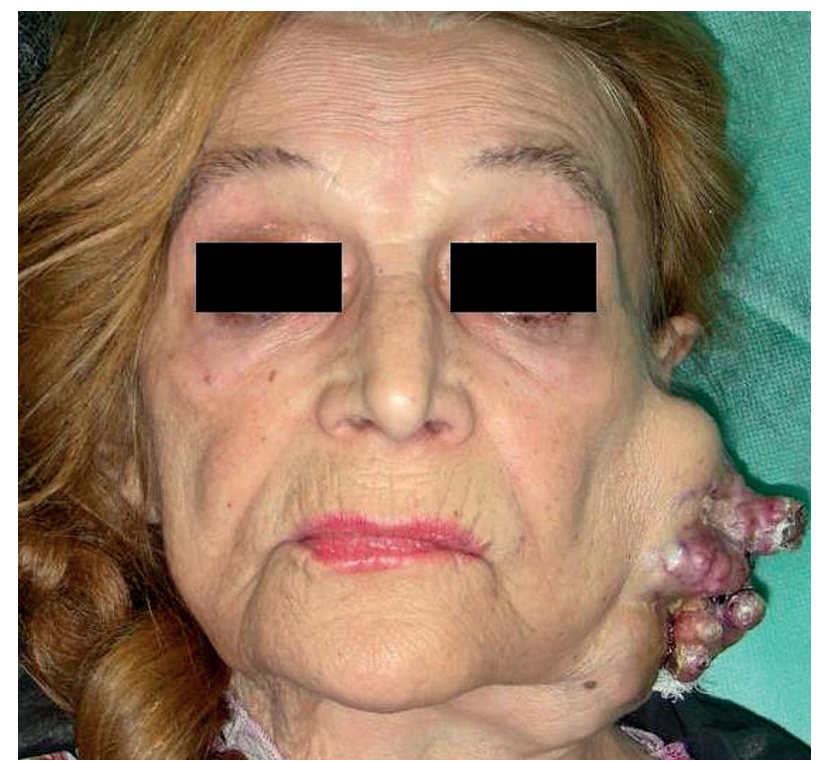

Fig. 1. Face of patient with left parotid gland tumour be extended to achieve the goal of treatment - clean surgical margins. Contralateral neck dissection is not routinely performed.

Radiotherapy is usually applied as an adjuvant treatment, especially in cases of tumour recurrence and positive surgical margins. Other indications for radiotherapy are: tumour in close proximity to the facial nerve, tumour of the deep lobe, regional lymph node metastases, extraglandular tissue spread, and the diameter of the tumour greater than $4 \mathrm{~cm}$ [15].

Acinic cell carcinoma survival rates after 5, 10 and 15 years are respectively $75 \%, 63 \%$ and $44 \%$, and the most frequent cause of failure is local recurrence followed by distant metastases and regional lymph node metastases [3, 5, 11].

The majority of acinic cell carcinoma cases are characterized by low clinical malignancy and susceptibility to the surgeon's treatment, even when there is extensive local progress. However, among them there is a group of highly malignant tumours which require associated post-operative radiotherapy. The proper identification of this ACC subgroups is of paramount importance for implementation of radiotherapy, while also allowing one to avoid the adverse effects of irradiation in patients who do not require such treatment [11].

\section{Case report}

In June 2008, an 80-year old woman with a huge, exophytic tumour of the left parotid gland was admitted to our department (fig. 1). She claimed she had been operated on for a pleomorphic adenoma of the left parotid gland in 1976 and 4 years after the primary excision a recurrent tumour appeared. Due to very slow growth, lack of subjective complaints and potential risk for the facial nerve during a secondary operation the patient refused surgical treatment. After almost 20 years, from 2000 the tumour became more aggressive, invading the skin of the pre-auricular area. Despite physician recommendations she rejected a proposal of surgical intervention. By the day of admission to our department the tumour had reached the size of $15 \times 15 \times 6 \mathrm{~cm}$. The polycyclic

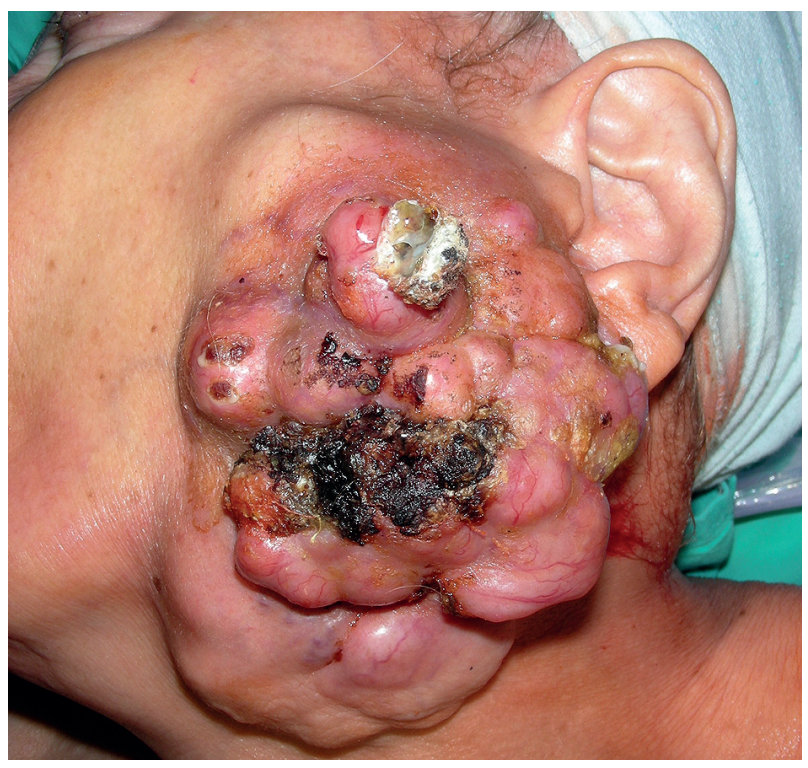

Fig. 2. The tumour immediately before the surgical procedure 


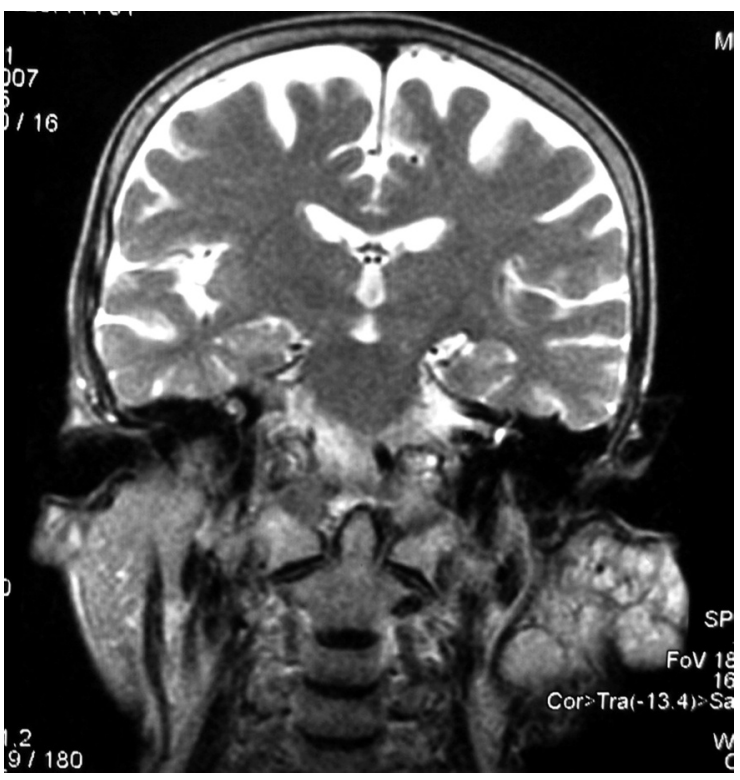

Fig. 3. Magnetic resonance imaging scan showing the polycyclic left parotid gland tumour

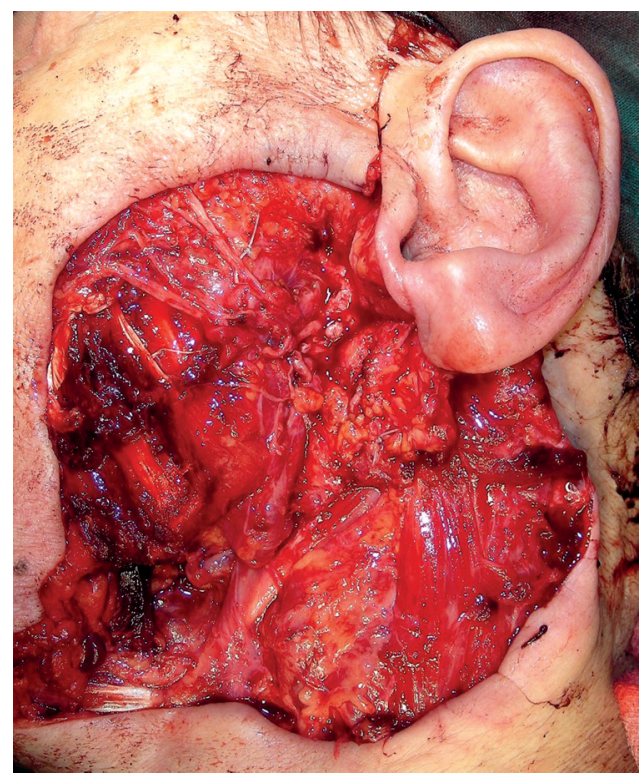

Fig. 5. Loss of tissue after removal of the left parotid gland tumour

surface of the elastic/hard neoplasm was covered by thin reddish skin with ulcerations on the top of finger-like tumour projections (fig. 2). Despite such a large tumour there was no facial nerve paralysis

A surgical biopsy was performed and on the basis of the histopathological examination the diagnosis of acinic cell carcinoma was established (WIM, Pathology Department J. Trawiński). Ultrasonography and MRI imaging showed the tumour reaching nearly $15 \mathrm{~cm}$ in diameter, disturbing the structure of the left parotid gland and the left masseter muscle and pushing the carotid arteries (external and internal) and internal jugular vein medially (fig. 3).

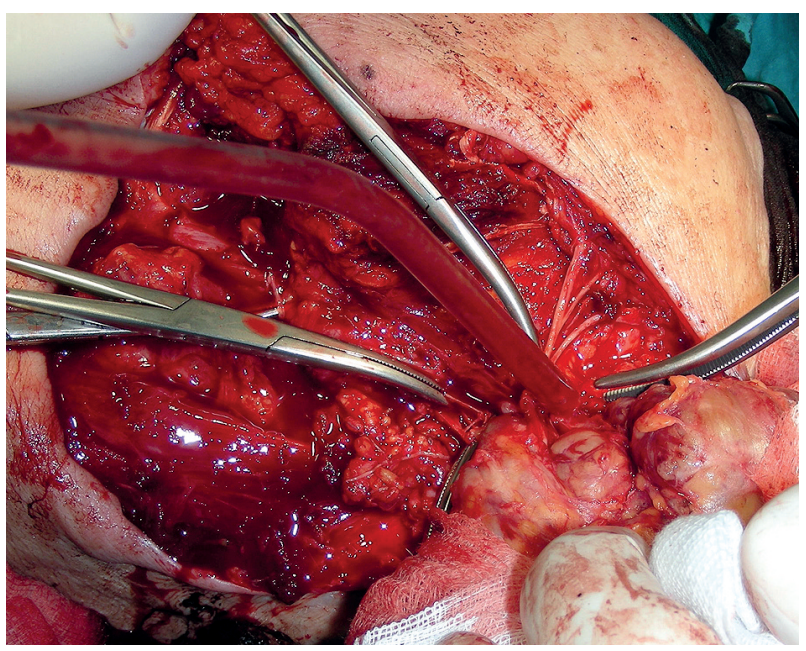

Fig. 4. The final stage of tumour resection. Visible temporal branches of the facial nerve that pass through the tumour mass. The inner surface of the tumour polycyclic

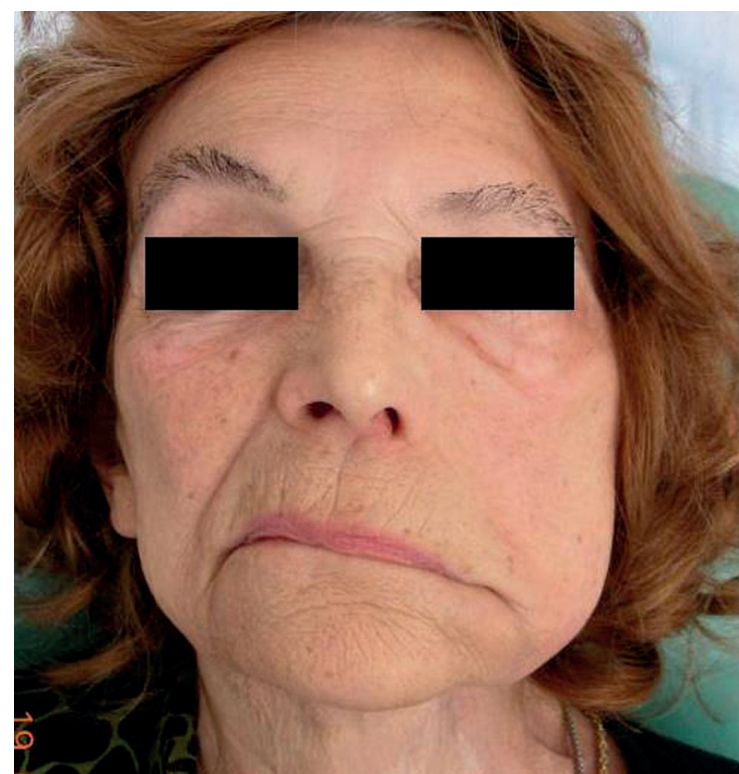

Fig. 6. Face of the patient one year after surgery. Visible features of left facial nerve paralysis

Total parotidectomy was carried out. The tumour was removed within the limits of inconspicuous tissues. We had to sacrifice a part of the branches of the facial nerve that penetrated through the tumour. The mandibular angle and the left masseter muscle were also removed due to invasion (fig. 4). Modified radical neck dissection (MRND m. III) with preservation of the accessory nerve, the internal jugular vein and the sternocleidomastoid muscle was performed. The ends of cut zygomatico-orbital and temporal branches of the facial nerve were reapproximated and microsurgically connected to its trunk. The facial skin defect was covered by an advancement-rotation musculo-cutaneous cervical skin flap (fig. 5). 


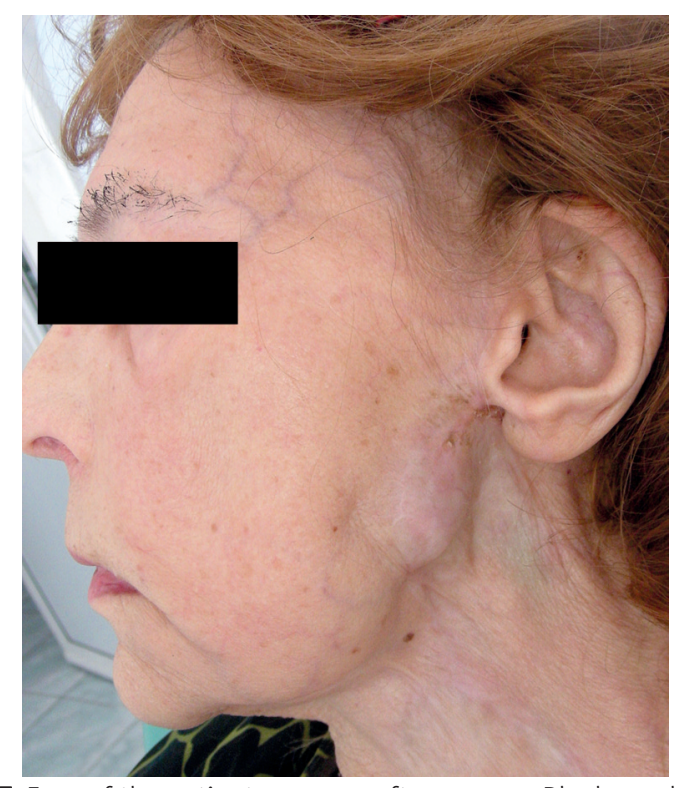

Fig. 7. Face of the patient one year after surgery. Blepharorrhaphy to prevent the formation of corneal ulceration

The postoperative period was complicated by necrosis of the top of the skin flap and prolonged healing. Post-operative histopathology examination revealed: acinic cell carcinoma low grade malignancy Ki-67 (+) less than 1\%. There were found foci of periosteal and bony invasion. No evidence of regional lymph node metastases (0/16). pT4a pNO pMx ICD-0 8550/3 WIM, Pathology Department - Dr J. Trawiński.

The function of the facial nerve did not recover, so it was necessary to narrow the palpebral fissure to prevent corneal desiccation and ulceration (fig. 6 and 7). Blepharorrhaphy was performed in November 2008. There are no signs of disease recurrence in 24 months of follow-up.

\section{Discussion}

The presented case of such an advanced acinic cell carcinoma of the parotid gland is a rarity in the literature [4]. In the present times, uncontrolled tumour expansion is precluded by quickly applied surgical treatment. Moreover, the low incidence of the tumour and its slow growth make the vast majority of these tumours impossible to develop to the extent described by us. Unlike most cases of ACC, the tumour despite its designation as a low-grade malignancy infiltrated the mandible, the masseter muscle and the preauricular skin. What is interesting, despite such large dimensions, the tumour did not cause facial nerve paralysis. Nevertheless, because of nerve VII interposition into the mass of the tumour, resection of its branches was required during surgery. An attempt of reconstruction of the nerve failed.

Preoperative diagnostic radiology did not show enlargement of lymph nodes of the neck. However, due to faster growth of the tumour immediately before surgery, ulceration of the surface and suspected infiltration of adjacent structures (cT4) it was decided to remove the ipsilateral cervical lymph nodes. Because of the low grade of the tumour, no lymph node metastases in the neck, clear surgical margins and advanced age, the patient did not decide on postoperative radiothera- py, although it is recommended by some authors in case of a significant locally advanced tumour [10, 12].

In our case the initial radical surgery can be considered as an appropriate method of treatment of highly differentiated acinic cell carcinoma.

\section{References}

1. Sikorowa L, Meyza JW. Guzy ślinianek. PZWL, Warszawa 1989.

2. Spiro RH, Huvos AG, Strong EW. Acinic cell carcinoma of salivary origin : a clinicopathologic study of 67 cases. Cancer 1978; 41: 924-33.

3. Gnepp DR, Henley JD, Simpson R, Eveson J. Salivary and Lacrimal Glands. In: Diagnostic surgical pathology of the head and neck Gnepp DR. Saunders 2nd edition 2009; 476-81.

4. Goldman NC, Lee J, Tolley B. Acinic cell carcinoma of the parotid gland. Otolaryngol Head Neck Surg 2007; 137: 828-9.

5. Ellis GL, Corio RL. Acinic cell adenocarcinoma. A clinicopathologic analysis of 294 cases. Cancer 1983; 52: 542-9.

6. Delides A, Velegrakis G, Kontogeorgos G, Karagianni E, Nakas D, Helidonis E. Familial bilateral acinic cell carcinoma of the parotid synchronous with pituitary adenoma: case report. Head Neck 2005; 27: 825-8.

7. Jamieson L, Taylor SM, Smith A, Bullock MJ, Davis M .Metastatic acinic cell carcinoma of the parotid gland with ectopic ACTH syndrome.Otolaryngol Head Neck Surg 2007; 136: 149-50.

8. Sang-il S, Hae Young S, Tai-kun K, Nam Jon L, Jung Hyuk K, Kyeong Ah K, Jeong-Soo W, Ju Han L. Acinic cell carcinoma of the head and neck : radiologic - pathologic correlations. J Comput Assist Tomogr 2005; 29: 121-6.

9. Drut R, Giménez PO. Acinic cell carcinoma of salivary glands with massive deposits of globular amyloid. Int J Surg Pathol 2008; 16: 202-7.

10. Skálová A, Sima R, Vanecek T, et al. Acinic cell carcinoma with highgrade transformation: a report of 9 cases with immunohistochemical study and analysis of TP53 and HER-2/neu genes. Am J Surg Pathol 2009; 33: 1137-45.

11. Gomez DR, Katabi N, Zhung J, Wolden SL, Zelefsky MJ, Kraus DH, Shah JP, Wong RJ, Ghossein RA, Lee NY. Clinical and pathologic prognostic features in acinic cell carcinoma of the parotid gland. Cancer 2009; 115: 2128-37.

12. Greig SR, Chaplin JM, Mclvor NP, Izzard ME, Taylor G, Wee D. Acinic cell carcinoma of the parotid gland. Auckland experience and literature review ANZ J Surg 2008; 78: 754-8.

13. Kim SA, Mathog RH. Acinic cell carcinoma of the parotid gland: a 15year review limited to a single surgeon at a single institution. Ear Nose Throat J 2005; 84: 597-602.

14. Laskawi R, Rodel R, Zirk A, Arglebe Ch. Retrospective analysis of 35 patients with acinic cell carcinoma of the parotid gland. J Oral Maxillofac Surg 1998; 56: 440-3.

\section{Address for correspondence}

\section{Jarosław Dąbrowsk}

Department of Maxillofacial Surgery

Military Institute of Medicine

128 Szaserów

04-141 Warsaw

e-mail: jardab78@interia.pl 